\title{
Investigation of the niche partitioning of selected Ranunculaceae species in Kosciuszko National Park along a soil moisture gradient, by comparison of hydraulic characteristics
}

\author{
Angela Stoddard, Tess Walsh Rossi, Cameron McArthur, \\ Sarah Stock, Ming-Dao Chia, Hannah Zurcher, Chen Liang, \\ Christine Mauger, Julia Hammer
}

\section{Abstract}

Environmental gradients that function as niche partitioning axes underpin plant biodiversity. Alpine zones are recognised biodiversity centres particularly threatened by a changing climate, which may alter such gradients. The soil water content (SWC) of coexisting Ranunculaceae in alpine and subalpine zones of Kosciuszko National Park, Australia (Caltha introloba, Ranunculus gunnianus, Ranunculus muelleri and Ranunculus graniticola) was investigated as a potential ecological niche division. We hypothesised that study species will be found in soils of distinct SWC, and hydraulic leaf characteristics will vary between species with respect to this gradient. As hypothesised, species were distributed along a statistically distinct soil water gradient $(P<0.001)$, with $C$. introloba found in soils of highest SWC. Whilst $R$. gunnianus was found in soils of higher mean SWC than the other Ranunculus species studied, the significance of this data could not be determined. In accordance with previous studies, the species of highest SWC, C. introloba, was found to have the leaf surface with highest stomatal density $(P<0.0001)$; highest adaxial stomatal density $(P<0.0001)$; largest xylem diameter; and lowest xylem density within a petiole section. Notably, a distinct trend of higher SLA for species of lower SWC was determined $(P<0.0001)$ in contradiction with the literature, which may have novel implications. 


\section{Introduction}

The coexistence of plant species within a community is commonly attributed to partitioning of resources. These partitions, or ecological niches, often reside along environmental gradients (Silvertown 2004). Niche segregation along such gradients has been described as vital to the success of large, biodiverse plant communities (Silvertown 2004). The characterisation of niche axes has been proposed as a means to model the ecological impacts of a changing environment (Buckley 2013). An observed trend towards homogenisation in ecosystems globally highlights the importance of understanding niche partitioning gradients that underpin plant biodiversity (Clavel et al. 2011).

Alpine environments have been recognised as biodiversity hot spots for flowering plants globally (Hörandl and Emadzade 2011). The Australian alpine region, in particular, has a very small geographical extent, with high endemism and floral diversity. These vegetation communities are under great threat by both climate change and human impacts (Edmonds et al. 2006; Worboys and Good 2011). Conservation of this diversity relies on a developed understanding of the niche systems underpinning the native alpine flora, which encompasses a suite of perennial herb species including the Ranunculaceae family.

Ranunculaceae, or the buttercup family, have shown high adaptive potential to alpine zones on a global scale (Hörandl and Emadzade 2011). Thus, they are a valuable model system relevant to a number of alpine environments worldwide. This study will aim to elucidate some major components of the niche partitioning systems between sympatric Ranunculaceae species within the subalpine and alpine ranges of Kosciuszko National Park. The study species-Caltha introloba, Ranunculus gunnianus, Ranunculus muelleri and Ranunculus graniticola (Costin et al. 2000)—coexist across a relatively small elevation gradient within alpine herb fields, and therefore are likely to have strong functional niche divisions.

The investigation of niche divisions in plants has been widely achieved by the assessment of functional traits (Buckley 2013). From such studies, soil water content has been identified as a major environmental axis in niche partitioning (Silvertown 2004). Leaf hydraulic traits of Ranunculus species have been shown to vary significantly along soil water gradients (Kołodziejek and Michlewska 2015). Such traits include adaxial and abaxial stomatal density, xylem diameter, xylem density and specific leaf area (SLA). 
In previous studies of Ranunculaceae species, stomatal density on both adaxial and abaxial surfaces has been reported to have a strong positive correlation with soil water content (SWC) (Lynn and Waldren 2002; Kołodziejek and Michlewska 2015). This correlation reflects an adaptive trade-off between water loss through evaporative transportation and influx of carbon dioxide for photosynthesis. A study of Ranunculus repens reported that individuals in wet soils had higher relative adaxial density (Lynn and Waldren 2002). This trend is consistently observed as water plants do not require stomata on the underside of submerged leaves, and are not limited by water loss from evaporative transpiration on adaxial surfaces (Xu and Zhou 2008).

In studies of the vascular characteristics of flowering plants under various soil moisture regimes, high SWC was strongly associated with larger mean xylem diameter and reduced xylem tissue as a percentage of petiole area (Awad et al. 2010). A large xylem diameter increases the efficiency of water conductivity in conjunction with embolism risk (Awad et al. 2010). As plants in high SWC have an exceptionally low embolism risk, wider xylem provides an adaptive advantage. It follows that increased water transport efficiency is associated with reduced investment in net xylem tissue.

Furthermore, high SLA is often associated with plants in high SWC, featuring leaves with high growth rates, high photosynthetic rates, a low carbon investment and relatively short lifespan. Conversely, a low SLA is associated with tough, long-lived leaves that are thick and/or have high dry matter content (Pérez-Harguindeguy et al. 2013). In previous studies of Ranunculus, thicker leaves with thicker epidermis were observed at drier test sites, typical of a low SLA (Cunningham et al. 1999; Kołodziejek and Michlewska 2015).

It has been previously hypothesised that the functional niches of the Ranunculaceae species studied so far are primarily partitioned by inhabiting soils of varied SWC (Armstrong 2003). Thus, this study will foremost aim to test the hypothesis that (1) R. graniticola, $R$. muelleri, $R$. gunnianus and $C$. introloba will be found in soils of significantly different SWC. Based on previous reports (Costin et al. 2000) we also predict that (2) C. introloba will inhabit areas of the highest SWC and (3) $R$. gunnianus may be characterised by soils of slightly higher SWC than $R$. graniticola and $R$. muelleri. 
We will investigate the aforementioned hydraulic characteristics of each species, and analyse them with respect to the SWC data collected. Based on trends observed in the literature, we hypothesise that species in areas of higher SWC will display (4) higher stomatal density, (5) higher relative adaxial stomatal density, (6) larger mean xylem diameter, (7) lower percentage xylem tissue per petiole area and (8) higher SLA.

\section{Methods}

The distribution of Ranunculaceae was observed along a transect from Charlotte Pass to Blue Lake (Table 1). Patches separated by at least $10 \mathrm{~m}$ were considered individual sites, from which one individual plant was sampled. Soil water content was measured using the Delta T Theta Probe, which was inserted into the soil at three points in an approximately triangular pattern around the plant to generate an average value.

Table 1: Local distribution of Ranunculaceae study species within Kosciuszko National Park.

\begin{tabular}{|l|l|l|}
\hline Species & Vegetation community & Sample size $(\mathrm{n})$ \\
\hline Caltha introloba & $\begin{array}{l}\text { Short alpine herbfield: often found below snow } \\
\text { patches and in snow melt streams. }\end{array}$ & 6 \\
\hline $\begin{array}{l}\text { Ranunculus } \\
\text { gunnianus }\end{array}$ & $\begin{array}{l}\text { Damp areas within tall alpine herbfield and sod } \\
\text { tussock grassland }\end{array}$ & 15 \\
\hline $\begin{array}{l}\text { Ranunculus } \\
\text { muelleri }\end{array}$ & Tall alpine herbfield and sod tussock grasslands & 23 \\
\hline $\begin{array}{l}\text { Ranunculus } \\
\text { graniticola }\end{array}$ & Tall alpine herbfield and sod tussock grasslands & 18 \\
\hline
\end{tabular}

The number of individuals of each species included in this analysis is given as the sample size.

Source: Adapted from Costin et al. (2000).

At each site, one sample plant was dug up minimising root mass disturbance, wrapped in damp paper towel and sealed in a plastic zip-lock bag. At least five samples of each species were collected from individual sites and stored in a cooler room at approximately $4^{\circ} \mathrm{C}$. These samples were utilised in further lab analysis of hydraulic characteristics: stomatal density, xylem diameter, xylem density and SLA. 


\section{Stomatal density}

Stomatal density was defined as the mean total area of stomata for a given area of leaf surface, given as a percentage. To measure this, leaves were randomly selected from collected samples $(n=2)$ of each species to generate stomatal peels. Leaves were pressed into a $1 \mathrm{~mm}$ film of super glue on a glass microscope slide, one abaxial and one adaxial side down. Once glue was set, leaves were removed leaving a negative impression. Slides were viewed and photographed under a light microscope at $100 \times$ magnification. Using the software ImageJ, the percentage area of stomata per leaf area was approximated by selecting random sample areas of $1 \mathrm{~mm}^{2}$. Random sampling of stomatal was performed twice per stomatal peel, resulting in a sample size of $(n=4)$ per species.

\section{Vascular profile}

Petiole sections were created from samples of each species $(\mathrm{n}=2)$ by slicing the hydrated petioles in a solid, stabilising medium with a razor. Sections were kept immersed in water, and dyed in a dilute Toluidine blue solution. Sections were transferred to a glass slide, covered with a cover slip and viewed under a light microscope. Petioles were photographed at $100 \times$ magnification, and vascular bundles at $400 \times$ magnification. ImageJ was used to measure the mean diameter of xylem vessels within samples from $400 \times$ images. Similarly, ImageJ was used to measure both the total area of the petiole section and the xylem tissue from $100 \times$ images. This data was expressed as xylem tissue as a percentage area of the petiole.

\section{Specific leaf area}

Specific leaf area (SLA) refers to the one-sided area of a hydrated leaf divided by its dry mass, measured in $\mathrm{cm}^{2} / \mathrm{g}$. The one-sided surface area of randomly selected leaves from samples ( $\mathrm{n}=5 ; \mathrm{n}=4$ for $R$. gunnianus) was measured using ImageJ to analyse scanned images. Leaves were then dehydrated by microwaving them between two pieces of cardboard on low-medium power for 2 minutes. Dry mass was determined using an electronic balance.

\section{Statistics}

Results were analysed using a two-way ANOVA test. Means with $P<0.05$ were considered significantly different. 


\section{Results}

The mean SWC of each Ranunculaceae sample site was found to vary significantly as predicted by hypothesis $(1)(P<0.001)$ (Figure 1$)$. The species occupying the sites of highest soil moisture was $C$. introloba as predicted (2) with a mean of 71.7 per cent, whilst $R$. graniticola sites had the lowest SWC of 19.7 per cent. There was, however, no significant difference evident between $R$. gunnianus and $R$. muelleri in SWC content, of 35.8 per cent and 30.7 per cent respectively. This data neither supports nor conflicts with hypothesis (3).

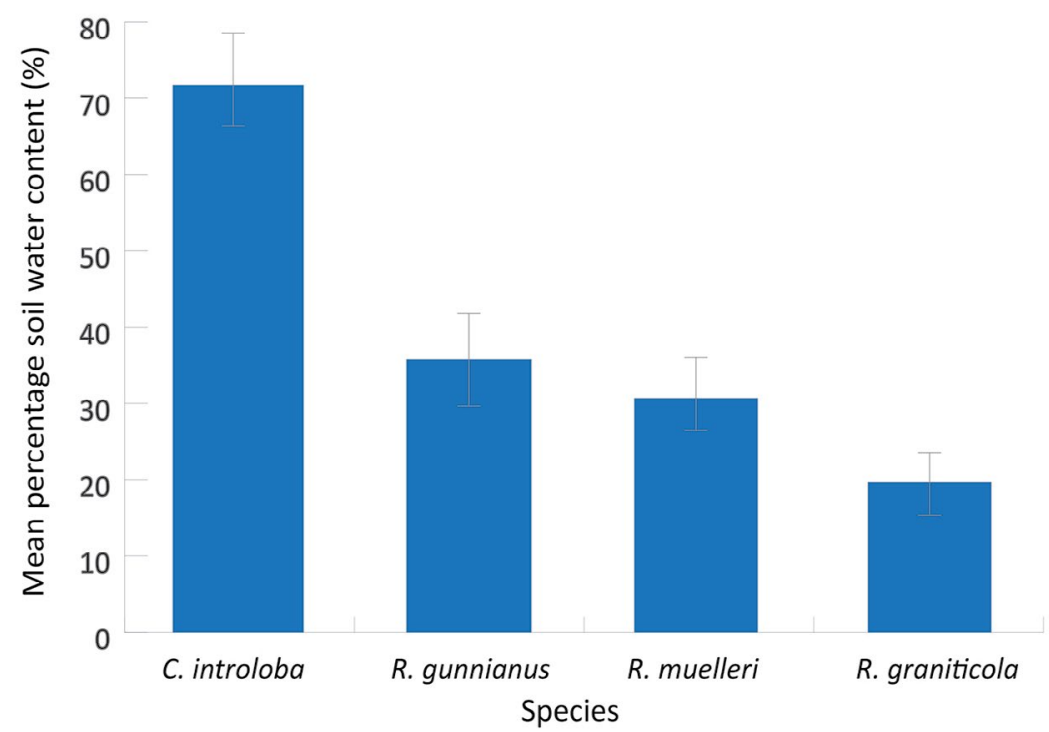

Figure 1: Mean percentage soil water content of Caltha introloba $(n=6)$, Ranunculus gunnianus $(n=15)$, Ranunculus muelleri $(n=23)$ and Ranunculus graniticola $(\mathrm{n}=18)$.

Note: Error bars are \pm SE. Using ANOVA, $P<0.001$.

Source: Results generated from field data using a soil moisture probe.

Mean stomatal density was not shown to have any significant or consistent correlation to soil moisture gradient as was anticipated (4) (Figures 2 and 3). However, the mean stomatal density was found to be significantly different between species on both abaxial $(P<0.0001)$ and adaxial $(P<0.0001)$ surfaces. As hypothesised (4), C. introloba displayed the highest stomatal density, 4.1 per cent. Notably, $C$. introloba stomatal density was exclusively found on the adaxial surface, which was not in conflict with expectations (5). 


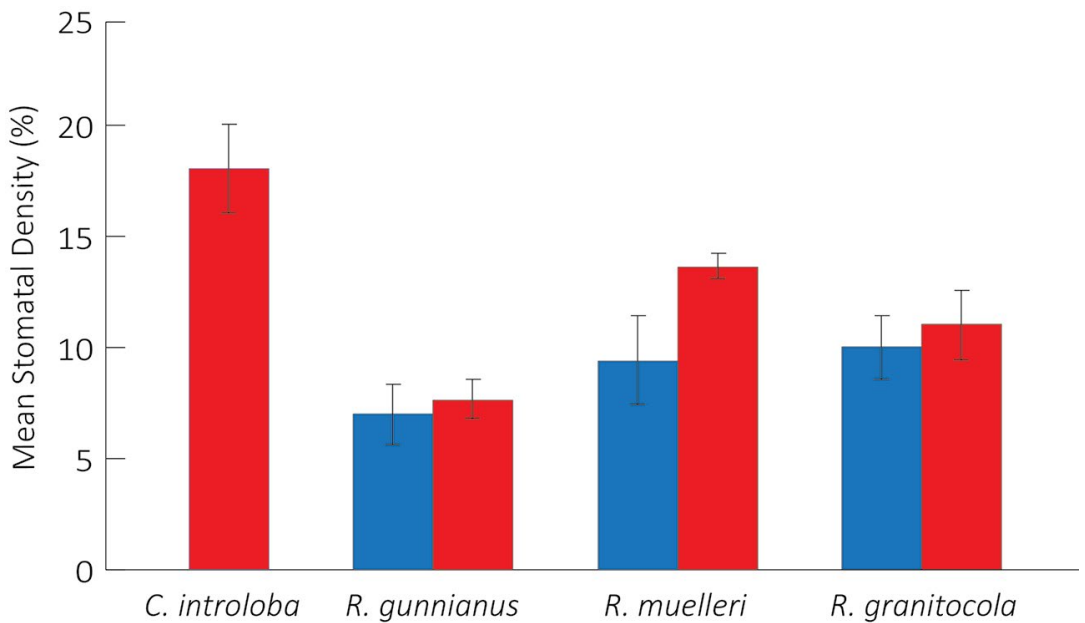

Figure 2: Mean stomatal density of the abaxial (blue) and adaxial (red) leaf surfaces of Caltha introloba, Ranunculus gunnianus, Ranunculus muelleri and Ranunculus graniticola. Sample size of $n=4$ in all species.

Note: Error bars are \pm SE. Using ANOVA, mean adaxial $(P<0.0001)$ and abaxial $(P<0.0001)$ stomatal densities were significant.

Source: Results generated by analysis of light microscope images of stomatal peels at $100 \mathrm{X}$ using ImageJ.

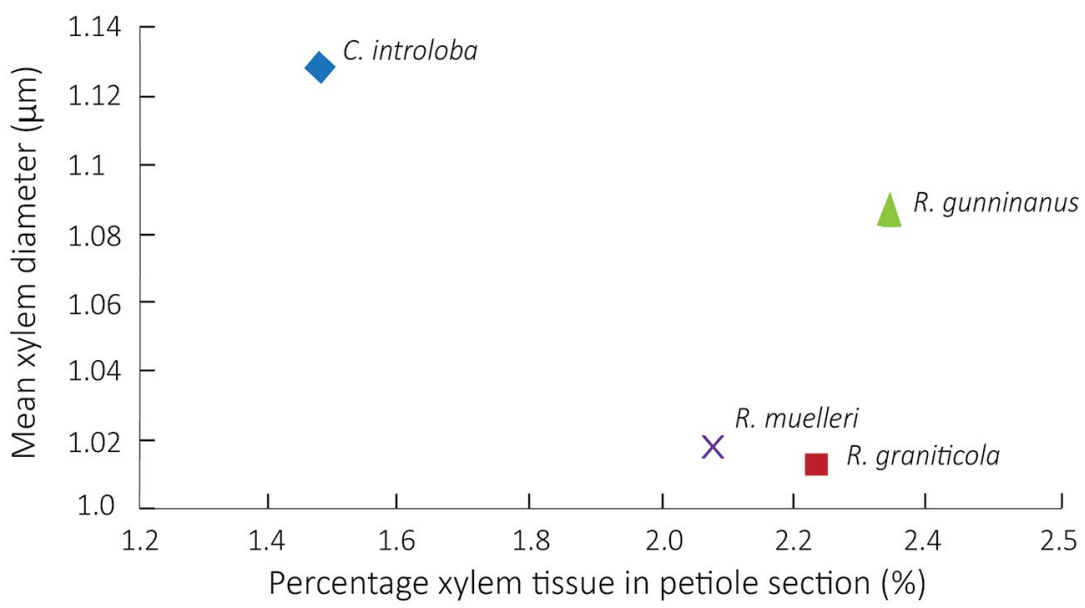

Figure 3: Mean diameter of xylem vessels and the percentage area of xylem tissue in a petiole section for Caltha introloba, Ranunculus gunnianus, Ranunculus muelleri and Ranunculus graniticola.

Note: Sample size of $n=2$ in all species.

Source: Results generated by analysis of light microscope images of petiole sections at 100X and 400X using ImageJ. 
The percentage xylem tissue in the total area of a petiole section and the mean diameter of xylem vessels supported some predicted trends (Figures 4 and 5). As hypothesised (6), C. introloba had the largest mean xylem diameter of $1.13 \mu \mathrm{m}$, and the lowest mean percentage of xylem tissue in the petiole section of 1.5 per cent (7). Whilst $R$. gunnianus had a similar percentage xylem tissue in the petiole as the other Ranunculus species, it had a notably larger mean xylem diameter. $R$. muelleri and $R$. graniticola did not vary significantly in either trait.

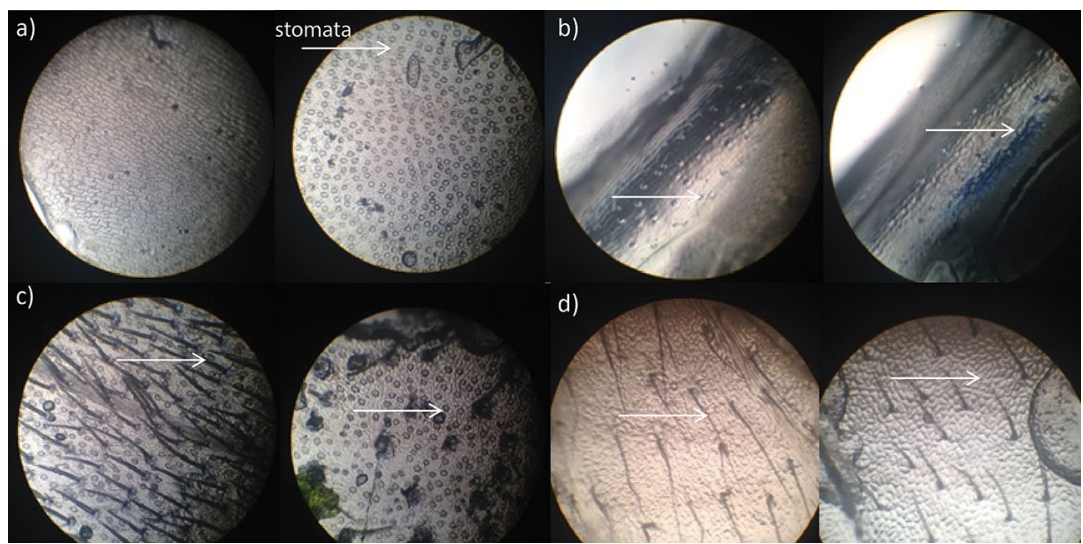

Figure 4: Images from light microscope at 100X magnification. Slides depict impressions of stomatal peels prepared using superglue adhesive. Left image in each pair is abaxial side, right image is adaxial: a) Caltha introloba, b) Ranunculus gunnianus, c) Ranunculus muelleri and d) Ranunculus graniticola.

Source: Authors' photograph.

SLA did not follow a positive trend with SWC as predicted (8) (Figure 6). In contradiction, $R$. graniticola, the species with lowest SWC, had a significantly larger SLA of $146 \mathrm{~cm}^{2} / \mathrm{g}$ than all other species $(P<0.0001)$. Overall, no consistent trend was observed along a soil moisture gradient.

\section{Discussion}

This investigation yielded ample evidence in support of the proposal of a soil moisture gradient comprising a functional niche division for the sympatric species Caltha introloba, Ranunculus gunnianus, Ranunculus muelleri, and Ranunculus graniticola in Kosciuszko National Park. Through the investigation of hydraulic characteristics, some correlations 
were observed in stomatal density and vascular composition with respect to this gradient as predicted. However, a potentially novel relationship was observed between SWC and SLA.

\section{Soil moisture gradient}

SWC varied significantly between the study species (1) (Figure 1), providing strong evidence in favour of SWC as a niche partitioning axis. As predicted (2), C. introloba was found in soils of the highest SWC. Whilst $R$. gunnianus was found in soils of slightly higher mean SWC than $R$. muelleri and $R$. graniticola (3), further investigation is required to substantiate this relationship. Notably, all observations were consistent with the literature (Costin et al. 2000). As soil water is arguably one of the most influential abiotic factors on plant life strategies (Silvertown 2004; Kołodziejek and Michlewska 2015), we expect the distribution of the species along this axis to also reflect trends in intrinsic hydraulic characteristics.

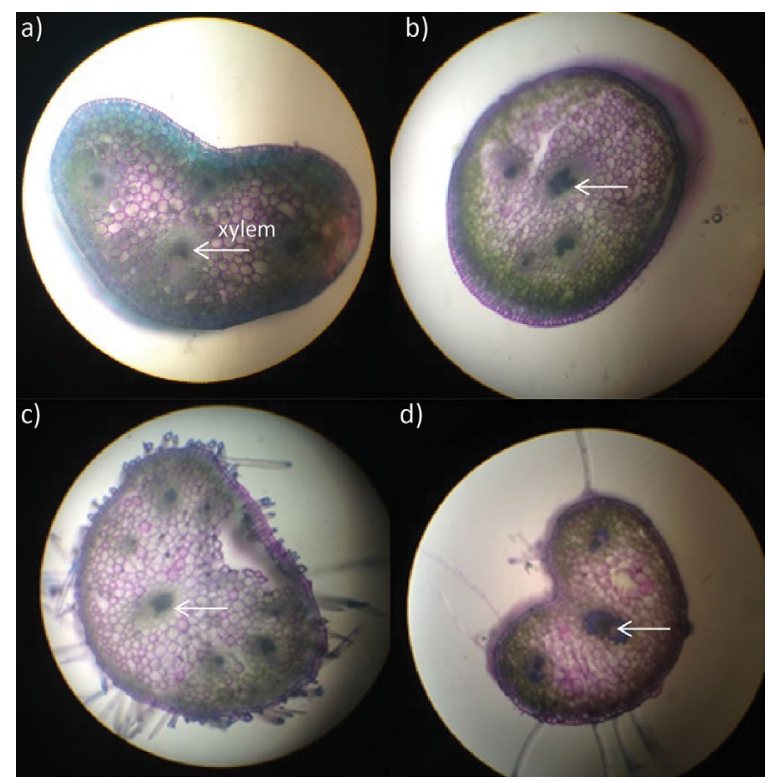

Figure 5: Images from light microscope at 100X magnification. Slides depict hydrated petiole sections, dyed using Toluidine Blue. As labels indicate, one example image is provided for each species studies: a) Caltha introloba, b) Ranunculus gunnianus, c) Ranunculus muelleri and d) Ranunculus graniticola.

Source: Authors' photograph. 
As the study species were found to be distributed along a SWC gradient, analysis of trends in hydraulic characteristics with respect to this gradient is assumed to be valid. We do note that data collection using the soil moisture probe was subject to human bias in selection of trial points. Sample sites and plants within sites were also selected with a slight bias in favour of visibility and accessibility. In general, this was a consequence of the large transect used, the use of artificial walkways, the limited access to sites in rough terrain and sites obscured by other landmarks or flora. This bias may have resulted in the preferential sampling of species from cleared areas or drier soils near the bare walkways.

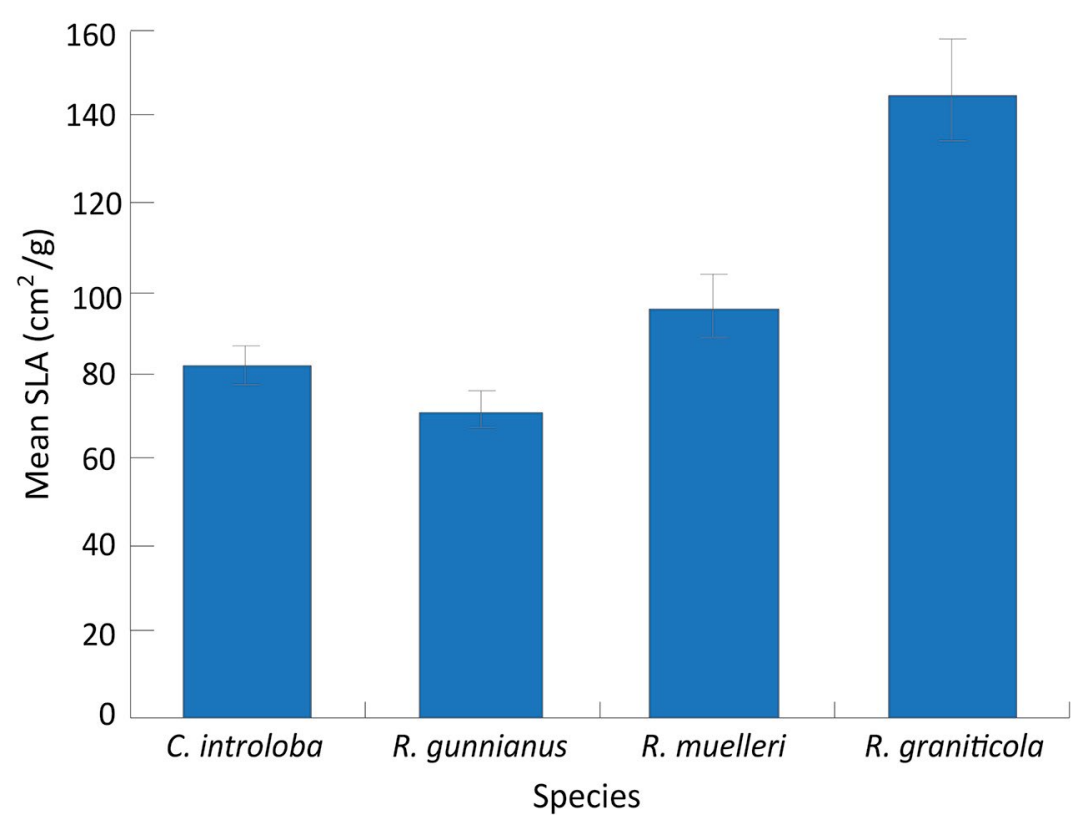

Figure 6: Graphical comparison of the mean SLA of Caltha introloba $(n=5)$, Ranunculus gunnianus $(n=4)$, Ranunculus muelleri $(n=5)$ and Ranunculus graniticola $(\mathrm{n}=5)$.

Note: Error bars are \pm SE. Using ANOVA, mean values were found to be significant $(P<0.0001)$.

Source: Authors' data.

\section{Stomatal density}

The highest mean stomatal density was observed in C. introloba, the species inhabiting the wettest soils (4) (Figures 2 and 3). As stomatal density positively correlates to gas exchange and carbon assimilation $(\mathrm{Xu}$ 
and Zhou 2008), we propose that $C$. introloba has adapted to capitalise on these traits given the high water availability. While this finding is in agreement with previous studies (Lynn and Waldren 2002; Kołodziejek and Michlewska 2015), no universal trend in stomatal density with respect to SWC was apparent in the data.

Furthermore, the adaxial stomatal density of $C$. introloba was significantly greater than all Ranunculus species as hypothesised (5) (Lynn and Waldren 2002). We also note that $C$. introloba stomatal density was exclusive to the adaxial surface, which is an adaptation common to plants partially submerged in water (Kirkham 2004).

We recognise potential sources of error in the microscope image analysis methodology. Images were taken using a hand-held camera to the eyepiece rather than an attached camera. The ImageJ software was calibrated once per magnification, whilst an accurate analysis of area and length would demand minor recalibrations for each image.

\section{Vascular profile}

Wider xylem and less percentage xylem tissue in a petiole section were observed for C. introloba, the species found in soils of highest SWC, as predicted (6)(7) (Figures 4 and 5). In accordance with SWC data, $R$. gunnianus also had notably wider xylem vessels than $R$. graniticola and $R$. muelleri. Whilst our data aligned with expectations, no significant trend could be established between vascular profile and mean SWC due to small sample sizes. We note that potential sources of error in microscope image analysis are relevant here, as previously described.

However, we recognise the biological significance of the trend between plant vascular profile and SWC that was observed. Wider xylem provides a functional advantage in water conduction efficiency (Awad et al. 2010). In high SWC, risk of xylem cavitation remains low, so adaptive trade-off tend to favour wide vessels (Awad et al. 2010). Likewise, reduced xylem tissue observed in C. introloba would conserve energy, as less vasculature is required to transport the equivalent water in high SWC.

Given the distinct vascular profile of $C$. introloba (Figure 4), the drying of soils and the disruption of water-flow patterns in the Australian Alps (Edmonds et al. 2006; Worboys and Good 2011) may have implications for species success in the future. As evidence indicates that $C$. introloba 
inhabit a niche partition at the high end of a soil moisture gradient, specialist vascular characteristics may endanger long-term species success within the landscape (Clavel et al. 2011). In particular, reduced SWC may result in higher rates of fatal embolism of the plant water column, which is associated with wide xylem. Trait plasticity experiments would be essential in predicting the extent of this effect.

\section{Specific leaf area}

SLA was significantly higher in study species found in drier soils, which directly refuted our hypotheses (8) (Figure 6). The highest SLA was recorded for $R$. graniticola, the species inhabiting the lowest SWC. The two lowest SLA values were recorded for $C$. introloba and $R$. gunnianus, which occupy the high end of the proposed soil moisture gradient. These results contradict previous studies that report that low SLA, and therefore greater long-term investment in leaf structure, is more strongly selected for in low water resource environments (Cunningham et al. 1999; Kołodziejek and Michlewska 2015).

A similarly unusual case of low SWC correlating with high SLA was observed in a study of silver birch trees, where individuals exposed to drought displayed an increase in SLA (Aspelmeier and Leuschner 2006). It was suggested that production of thinner, less costly leaves in drought conditions was the cause of high SLA. However, a high SLA in low SWC remains a highly unusual result for plant species (Pérez-Harguindeguy et al. 2013), which may be due to inadequacies of the experimental method.

A potential reason for the novel results generated is related to the atypical leaf drying method (Pérez-Harguindeguy et al. 2013). In the case of partial dehydration, species from high SWC like $C$. introloba may have retained more water, leading to the lower SLA observed. Alternatively, pronounced differences in growth and/or flowering times (Pickering 1995) may have resulted in smaller leaves in species from high SWC, again skewing results. Further experimentation is required to determine if this novel result is valid, which may suggest interesting biological implications.

\section{Future directions}

Future direction may involve both refining and broadening the scope of this experiment. To refine, larger sample sizes using standardised techniques and units would greatly enhance the quality and comparability 
of data generated. In determining soil water content, a more robust sampling regime is recommended for future investigation. For further studies of stomatal density and vascular data, use of a mounted camera on the light microscope is suggested to ensure accurate image analysis. Additionally, the expression of stomatal density in number $/ \mathrm{mm}^{2}$, a widely utilised unit, would increase comparability with previous studies (Kołodziejek and Michlewska 2015). We also recommended that leaves be oven-dried to determine dry mass for SLA calculations as outlined in the literature (Pérez-Harguindeguy et al. 2013).

Furthermore, a broader scope of study may investigate other hydraulic characteristics, such as xylem conductivity, leaf water potential, vulnerability to embolism, root system morphology (Pérez-Harguindeguy et al. 2013), pubescence, epidermal thickness, relative conductivity of adaxial and abaxial stomata (Kołodziejek and Michlewska 2015) and water use efficiency (Xu and Zhou 2008).

In addition to this, investigation of the plasticity of the hydraulic traits studied would be a valuable addition to this area of study. Our experimental design relies on the assumption that the trends in phenotype are predominantly genotypic, or that plants only successfully inhabit soils of approximately the same SWC in which they were observed. Examining the plasticity of these traits in response to varied SWC in a greenhouse setting would allow a more refined understanding of the strength of SWC as a niche division, as well as an enhanced ability to make predictions about the fate of Ranunculaceae in the Australian Alps.

In addition, more species of Ranunculaceae within the same distribution may be investigated, in the context of appropriate permits: $R$. anemoneus, $R$. millani, R.dissectifolius and R. niphophilus (Costin et al. 2000). This would support a much more comprehensive profile of Ranunculaceae niche partitioning in the Kosciuszko alpine and subalpine zone.

\section{Conclusions}

We found substantial evidence of niche partitioning of $C$. introloba, $R$. gunnianus, $R$. muelleri and $R$. graniticola along a soil water gradient (1), with $C$. introloba found in soils of highest SWC as predicted (2). However, found only weak evidence that $R$. gunnianus inhabits a niche of higher SWC than $R$. muelleri and $R$. graniticola (3). 
Through comparative analysis, hydraulic traits were found to correlate to relative SWC in some cases. The species found in highest SWC, $C$. introloba, was found to have the leaf surface with highest stomatal density (4) and highest relative adaxial stomatal density (5) as predicted. However, this trend was not observed across all four species. Likewise, $C$. introloba was observed to have wider xylem (6) and a low relative density of vascular tissue (7) within a petiole section as hypothesised. . gunnianus, found to occupy a slightly higher position along the SWC gradient, was also observed to have wider xylem than other Ranunculus species. However, vascular observations were limited due to the small sample size. Notably, a distinct trend of higher SLA for species of lower SWC was determined in contradiction with the literature (8), which may have novel implications.

\section{Acknowledgements}

Thanks to the Research School of Biology and The Australian National University for providing all of the equipment and support to make this research possible. Thank you to NSW National Parks and Wildlife Services for allowing us to undertake this field study within Kosciuszko National Park. Lastly, thank you to the Southern Alps Ski Lodge for their generosity in hosting the group. We thank the resource people for their guidance.

\section{References}

Armstrong T (2003) Hybridization and adaptive radiation in Australian alpine Ranunculus. PhD thesis, The Australian National University.

Aspelmeier S, Leuschner C (2006) Genotypic variation in drought response of silver birch (Betula pendula Roth): Leaf and root morphology and carbon partitioning. Trees - Structure and Function 20: 42-52. doi. org/10.1007/s00468-005-0011-9

Awad H, Barigah T, Badel E, Cochard H, Herbette S (2010) Poplar vulnerability to xylem cavitation acclimates to drier soil conditions. Physiologia Plantarum 139: 280-8. doi.org/10.1111/j.13993054.2010.01367.x 
Buckley LB (2013) Get real: Putting models of climate change and species interactions in practice. Annals of the New York Academy of Sciences 1297: 126-38. doi.org/10.1111/nyas. 12175

Clavel J, Julliard R, Devictor V (2011) Worldwide decline of specialist species: Toward a global functional homogenization? Frontiers in Ecology and the Environment 9: 222-8. doi.org/10.1890/080216

Costin AB, Gray M, Totterdell CJ, Wimbush DJ (2000) Kosciuszko Alpine Flora, 2nd edn. CSIRO Publishing, Melbourne.

Cunningham S, Summerhayes B, Westoby M (1999) Evolutionary divergences in leaf structure and chemistry, comparing rainfall and soil nutrient gradients. Ecological Monographs 69: 569-88. doi. org/10.1890/0012-9615(1999)069[0569:EDILSA]2.0.CO;2

Edmonds T, Lunt I, Roshier D, Louis J (2006) Annual variation in the distribution of summer snowdrifts in the Kosciuszko alpine area, Australia, and its effect on the composition and structure of alpine vegetation. Austral Ecology 31: 837. doi.org/10.1111/j.14429993.2006.01642.x

Hörandl E, Emadzade K (2011) The evolution and biogeography of alpine species in Ranunculus (Ranunculaceae): A global comparison. Taxon 60: 415-26.

Kirkham MB (2004) Principles of Soil and Plant Water Relations. Elsevier Academic Press, USA.

Kołodziejek J, Michlewska S (2015) Effect of soil moisture on morphoanatomical leaf traits of Ranunculus acris (Ranunculaceae). Polish Journal of Ecology 63: 400-13. doi.org/10.3161/15052249PJE2015.63.3.010

Lynn DE, Waldren S (2002) Physiological variation in populations of Ranunculus repens L. (Creeping buttercup) from the temporary limestone lakes (turloughs) in the west of Ireland. Annals of Botany 89: 707-14. doi.org/10.1093/aob/mcf125

Pérez-Harguindeguy N, Díaz S, Garnier E, Lavorel S, Poorter $\mathrm{H}$, Jaureguiberry P, Bret-Harte MS, Cornwell WK, Craine JM, Gurvich DE, Urcelay C, Veneklaas EJ, Reich PB, Poorter L, Wright IJ, Ray P, Enrico L, Pausas JG, de Vos AC, Buchmann N, Funes G, Quétier F, Hodgson JG, Thompson K, Morgan HD, ter Steege H, van der 
Heijden MGA, Sack L, Blonder B, Poschlod P, Vaieretti MV, Conti G, Staver AC, Aquino S, Cornelissen JHC (2013) New handbook for standardised measurement of plant functional traits worldwide. Australian Journal of Botany 61: 167-234. doi.org/10.1071/BT12225

Pickering CM (1995) Variation in flowering parameters within and among five species of Australian alpine Ranunculus. Australian Journal of Botany 43: 103-12. doi.org/10.1071/BT9950103

Silvertown J (2004) Plant coexistence and the niche. Trends in Ecology and Evolution 19: 605-11. doi.org/10.1016/j.tree.2004.09.003

Worboys GL, Good RB (2011) Caring for our Australian Alps Catchments: Summary Report for Policy Makers. Department of Climate Change and Energy Efficiency, Canberra.

Xu Z, Zhou G (2008) Responses of leaf stomatal density to water status and its relationship with photosynthesis in a grass. Journal of Experimental Botany 59: 3317-25. doi.org/10.1093/jxb/ern185 
This text is taken from Researching functional ecology in Kosciuszko

National Park, edited by Hannah Zurcher, Chia Ming-Dao, Michael Whitehead and Adrienne Nicotra, published 2017 by ANU eView, The Australian National University, Canberra, Australia. dx.doi.org/10.22459/RFEKNP.11.2017.01 